\title{
Differences between Spanish and foreign workers in the duration of workplace accident leave: a stochastic frontier analysis
}

\author{
ANGEL L. MARTÍN ROMÁN \\ (University of Valladolid) \\ ALFONSO MORAL DE BLAS \\ (University of Valladolid) \\ e-mail of contact: angellm@eco.uva.es
}

\begin{abstract}
:
The main goal of the current work is to analyse differences between the working conditions of national and foreign workers in Spain. For this purpose, we study an important dimension of said working conditions, namely workplace injuries, and more specifically the differences in duration of occupational injury leave as a consequence of work-related accidents. The empirical analysis is carried out using stochastic frontier techniques. This allows a minimum period off work due to merely physiological or medical reasons to be distinguished from an additional period linked to worker behaviour. This latter component measures inefficiency in frontier literature, and is identified in the present work as a relevant indicator of working conditions. The findings reveal that most of the differences observed between national and immigrant workers in said duration are a result of the inefficiency term. For the purpose of the current work, this is reflected in poorer working conditions for immigrant workers, particularly for those from less developed countries.
\end{abstract}

Keywords: workplace accidents, immigration, stochastic frontiers.

Classification JEL: J28, J61, J81 


\section{INTRODUCTION.}

The current work seeks to explore the contrasting working conditions of national and foreign workers in the Spanish labour market. This topic is usually analysed by comparing the differences in the wage received by the two groups, in other words by exploring the issue of labour discrimination. One different approach has been to analyse differences in labour market entry $^{1}$ or the termination of the contractual relationship ${ }^{2}$. The present research focuses on a relatively unexplored area: differences in sick leave duration resulting from work accidents.

Sick leave duration is a far more complex issue than would at first appear. When comparing mean duration among different groups (for instance national and foreign workers), this measure proves extremely sensitive to the number of minor accidents reported. For this reason, working with microdata which enable the nature and severity of the injury to be taken into account proves extremely enlightening. One further aspect worth mentioning is that sick leave duration embraces two clearly distinguishable components: one which is eminently medical, and relates to a person's natural period of recovery subsequent to an injury, and another that is based on economic foundations, and is linked to a person's ability to decide, and potentially engage in opportunistic or strategic behaviour. It is this latter aspect which has been the focus of most attention in the economic literature, particularly with regard to the matter of absenteeism, and which has been rationalized in terms of "moral hazard" when workers' compensation systems are involved.

In our view, the two components differ, which is why we consider they merit being treated differently From an econometric standpoint, we employ stochastic frontier techniques to distinguish said components. Estimating a lower or "cost" frontier, determined by essentially medical factors, allows us to measure minimum sick leave duration, which we here interpret as an indicator of the unavoidable period required for a worker to return to work after regaining an acceptable state of health. Actual sick leave duration will exceed said minimum, the difference being attributable to behaviour based on the rational decisions taken by the "homo economicus" of microeconomic theory. We thus model said difference, the "inefficiency" term, within stochastic frontier literature, by means of what are essentially economic variables such as the type of contract, worker compensation while off work, which sector of the economy workers are involved in, and so on.

The economic literature addressing sick leave duration from the perspective of work absenteeism and work accidents has tended to treat all the days taken off equally. We believe that distinguishing between "medical days off"

\footnotetext{
${ }^{1}$ Certain studies have been conducted into whether, for instance, immigrant workers enter the labour market with worse contracts (for instance with temporary rather than open-ended contracts).

${ }^{2}$ Here, the topic explored is whether foreign workers are dismissed more readily than their national counterparts.
} 
and "economic days off" will enable us to explore the issue at hand more accurately. Our main interest lies in "economic days off". Exploring the differences observed between the two for national and immigrant workers provides the work's main findings. We make the reasonable assumption that a worker who enjoys more favourable working conditions, mainly better employment protection, will be able to prolong "economic days off". Comparing differences in the "inefficiency" part of the stochastic frontier estimation reveals that foreign workers enjoy fewer "economic days off". This provides the basis for the present work and is what we will attempt to explain in the remainder thereof.

The rest of the paper is organised as follows. Section two gives an overview of the literature exploring the differences to emerge in the labour market between national and foreign workers, focusing particular attention on the case of Spain. Section three details the approach used to obtain the main results. As already pointed out, the method adopted applies econometric techniques based on "stochastic frontiers". Section four sets out and describes the database used in the work: Statistic of Accidents at Work (SAW). Said section also offers some descriptive information prior to the subsequent, more rigorous, econometric analysis. Section five discusses the main findings to emerge from a two-fold perspective: the first dealing with the parameters estimated using multivariate regression analysis, and the second comparing estimations of "medical days off" and "economic days off" for national and immigrant workers. The final section presents the main conclusions.

\section{BACKGROUND.}

Over the last few years numerous works have explored the situation of the immigrant population in labour markets. The bulk of this literature has focused on analysing the impact on both job opportunities and wages for national workers as well as how foreign workers have fitted into the host country's labour market. Comprehensive reviews of this literature at an international scale may be found in the works of Borjas (1999), Friedberg and Hunt, (1995), Lalonde and Topel (1997), and Card (2005).

Studies exploring the impact of immigration on the Spanish labour market have proliferated in recent years in line with the substantial increase in the influx of immigrant workers in the years immediately prior to the onset of the crisis. A thorough review of such studies may be found in Simón et al. (2008), which details works offering an overview of the immigration situation in the Spanish labour market (Izquierdo and Jimeno, 2005; Garrido and Toharia, 2003 and Carrasco et al., 2003) as well as works focusing on more specific issues such as occupational segregation, unemployment discrepancies, and wage gaps. Dolado et al. (1997) report a positive effect of the immigrant regularization introduced in the early 1990s on 
unemployment rates and wages. Amuedo-Dorantes and De la Rica (2010) report localised emigration towards areas with higher employment rates. Carrasco et al. (2008) report a slight effect of immigration on national employment, an effect in part determined by immigrant levels of assimilation.

For the case of Spain, a further stream of research specifically explores immigrant worker assimilation, in other words, immigrant worker performance compared to national workers. Based on a comparison carried out over time of an array of labour indicators linked to different groups of workers, Iglesias and Llorente (2008) report that there is no clear process of assimilation in immigrant worker practices when they are compared with those of national. Amuedo-Dorantes and De la Rica (2006) find that immigrants are segregated in low paid jobs, and also report greater immigrant occupational mobility as the length of their stay in Spain increases. Sanromá et al. (2006) explore immigrant worker wage assimilation based on the close relationship between educational attainment and wage differences, and report a greater impact of over-education among immigrant workers, which is responsible for much of the wage gap between national and immigrant workers. Simón et al. (2008) investigate wage differences directly, and find that such gaps may to a large extent be accounted for by differences in where immigrants locate and what jobs they take up. Finally, after taking into account personal and work-related variables, Medina et al. (2010) report that foreign workers are more likely to lose their jobs, although this finding only proved significant during the crisis.

An issue that has not received much attention in the literatureis the link between immigrant labour and health and safety problems at work. Some empirical works for the United States report a greater risk of occupational accidents in coloured workers. (Worrall and Butler, 1983; Butler and Worrall, 1983; Bartel and Thomas, 1985; and Graham and Shakow, 1990, Richardson et al., 2004). For the period 1996-2001, Richardson and Loh (2004) report an increase in the risk of fatal occupational accidents among immigrants in the United States (particularly those from Latin America) as opposed to a drop in the risk observed among national workers. In a study carried out in Germany, Bauer et al. (1999) report that German work safety legislation has proven effective in curtailing minor accidents regardless of worker origin.

For Spanish data, Ahonen and Benavides (2008) find less risk of suffering both fatal as well as non-fatal accidents among immigrant workers. Moral et al. (2010) explore the relatively greater number reported of so-called "hardto-diagnose accidents" suffered by national workers. Said work concludes that most differences are not the result of the covariates included in the model and therefore reflect a greater effort and job commitment on the part of immigrant workers. 
The present work seeks to provide further insights into this topic from a different perspective. The dependent variable studied here captures the duration of sick leave resulting from workplace accidents, the aim being to explore the differences to emerge when comparing national and immigrant workers. Thus, workers who are off for longer periods, when no medical or physiological reasons are apparent, are deemed to be enjoying more favourable working conditions.

\section{METHODODOLOGY.}

Studies analysing the duration of accident related sick leave in the economic literature have applied a number of different estimation techniques. Many of these works employ simple econometric regression techniques applying ordinary least squares (OLS). Other authors use the "natural experiments" approach to gauge changes in legislation which may affect sick leave duration. Researchers have recently begun to apply "hazard models" which outperform simple regression models when analysing duration, particularly when data censoring exists.

In the present work, a different approach is adopted, which we feel provides new and innovative contributions to the research area in question. We believe that there is a standard duration $\left(D_{i}^{S}\right)$ for sick leave, which may be attributed to medical or physiological reasons and which would determine a lower limit. Said minimum recovery spell required to return to work may be defined by the following expression:

$d_{i}^{S}=X_{i} \beta+v_{i}$

where $d_{i}^{S}$ is the logarithm of the minimum duration $\left(d_{i}^{S}=\ln \left(D_{i}^{S}\right)\right), X_{i}$ is a vector of individual characteristics, $\beta$ is a vector of coefficients, and $v_{i}$ is a random error of mean 0 and variance $\sigma_{v}^{2}$.

Yet, there is an information problem which prevents the minimum duration being known by the insurer, who only perceives the actual duration $\left(D^{r}\right)$ which normally exceeds the standard duration $\left(D^{r} \geq D^{s}\right)$ and which, in addition to the medical and physiological aspects mentioned earlier, is the result of workers' ability to enjoy an additional period of recovery. This ability would reflect an opportunistic behaviour on the part of the worker, indicating how secure they perceive their job situation to be ${ }^{3}$. Obviously, greater job security would be linked to better working conditions that would enable the worker to engage more intensely in such an opportunistic behaviour. This leads us to conclude that we face a problem of asymmetric information linked to insurance firms monitoring workers during their absence from work.

\footnotetext{
${ }^{3}$ Such behaviour has often been reported in the literature addressing work absenteeism and in the literature exploring issues of moral hazard linked to work accident insurance.
} 
There is thus a real duration which is the result of adding the standard duration to a non-negative random disturbance. Said standard duration forms a lower frontier ${ }^{4}$ that may be estimated based on characteristics such as age, gender, or the nature of the injury, which determine the length of recovery time, and are based on physiological factors.

$d_{i}^{r}=d_{i}^{S}+u_{i}$

where $d_{i}^{r}$ is the logarithm of the actual duration $\left(d_{i}^{r}=\ln \left(D_{i}^{r}\right)\right)$, and $u_{i}$ is another error term with a positive mean and variance $\sigma_{u}^{2}$. In order to ensure that the model may be estimated, $u_{i}$ must follow a certain statistical distribution. The literature offers several examples of distributions that allow estimations to be carried out. Aigner et al (1977) use a semi-normal distribution, Meeusen and van den Broeck (1977) opt for an exponential distribution, Stevenson (1980) employ a normal truncated distribution, Green (1980a and 1980b) preferring a gamma distribution. Based on (1) and (2), we obtain the following expression:

$d_{i}^{r}=X_{i} \beta+v_{i}+u_{i}$

Having a composed error model means that estimation through ordinary least squares does not prove the most suitable. Provided that disturbances and regressors are independent, ordinary least square estimators are unbiased, consistent, and efficient among linear estimators. There is, however, inconsistency in the constant term, and variances of both disturbances cannot be separated ${ }^{5}$. As a result, maximum likelihood estimation using the stochastic frontier technique proves more appropriate.

The same technique allows the disturbance distinguishing actual and standard durations to be modelled. Following Battese and Coelli (1995), the effects of inefficiency may be explained based on a vector $\mathrm{Z}$ of explanatory variables in line with the following expression:

$u_{i}=Z_{i} \varphi+\omega_{i}$

where $\varphi$ is a vector of parameters to be estimated, and $\omega_{i}$ is a random variable which comes from a normal truncated, semi-normal, exponential, or gamma distribution. Thus, in order to ensure that random disturbance related to inefficiency maintains its positive value, $\omega_{i} \geq-Z_{i} \varphi$ has to be fulfilled. In this case, maximum likelihood estimation, albeit more complex, does allow $\beta, \varphi, \sigma_{v}^{2}$ and $\sigma_{u}^{2}$ to be obtained jointly.

\footnotetext{
${ }^{4}$ Within the methodological framework of the present work, this lower frontier is linked to what is termed the cost frontier in the literature.

5 Not being able to estimate the value of the variances separately prevents from carrying out the necessary tests so as to validate the existence of inefficiency.
} 
Using stochastic frontiers for the analysis also allows estimations of $u_{i}$ to be obtained through the mean or the mode of $f\left(u_{i} / \varepsilon_{i}\right)$, knowing that $\varepsilon_{i}=v_{i}+u_{i}$ (Jondrow et al. 1982). Finally, it is possible to calculate for each individual the value of their cost efficiency using the following expression:

$E F=\frac{f\left(X_{i} \beta\right) \exp \left(v_{i}+u_{i}\right)}{f\left(X_{i} \beta\right) \exp \left(v_{i}\right)}=\exp \left(u_{i}\right)$

\section{DATA.}

As pointed out in the introduction, the present work seeks to pinpoint the differences in working conditions between national and immigrant workers. The literature has already addressed said differences from a variety of angles such as wages, contracts or unemployment rates. The present work adopts a new perspective to explore these differences; workplace accidents. As a consequence of this fact, our dependent variable will be sick leave duration resulting from workplace accidents. Given our choice, the database which provides the best information is the SAW elaborated by the Ministry of Labour. This is an annual register of any work-related accidents occurring in Spain that entail sick leave. Moreover, said database provides information concerning workers characteristics, accidents, injuries, and the jobs in question.

For the present work, we used data from the years 2007 and 2010. This thus provided us with information from two contrasting cyclical situations (boom and downturn) so as to identify and measure the impact the economic situation has on sick leave duration. One point worth remembering is that during said period the unemployment rate in Spain soared from near 8\% to over $20 \%$.

After having carried out data cleansing, information was available from $1,370,477$ work-related accidents corresponding to salaried workers, and which led to at least one day off work and did not result in the death of the worker. Of these, 773,709 correspond to 2007 and 596,768 to 2010. Moreover, nearly $9 \%$ of the total are related to immigrant workers $(139,101$ accidents over the two years). Finally, it was decided to distinguish between immigrant workers depending on their origin. We thus drew a distinction between two groups of countries; more advanced countries including Western Europe, North America, and Oceania, on the one hand and the less advanced countries on the other hand.

An initial review of the data revealed that national worker sick leave duration exceeded that of developed country workers by two days and that of nondeveloped country workers by seven days. Translated into percentage terms, this means that national worker sick leave duration is 33\% longer than that of their non-advanced country counterparts. Added to the fact that the 
accident incidence rate is lower for immigrant workers ${ }^{6}$ would seem to indicate that foreign workers suffer fewer accidents and that these are less serious.

\section{(Insert table 1)}

Yet, closer scrutiny might change our initial appraisal of these figures. The data shown in table 1 reveal shorter sick leave periods among immigrant workers regardless of the nature of the injury, its severity or the activity in which the worker suffering the accident is involved. Said difference is particularly significant when compared to workers from less advanced countries. This does not therefore mean that immigrant workers suffer less important injuries but that the same injury entails more time off among Spanish workers. This finding would seem to point to poorer working conditions among non-national workers, which translates to shorter recovery times, and which is particularly noticeable in the case of immigrants from less developed countries.

Another two variables which prove interesting in the analysis are the impact of the crisis and gender differences. In line with National Work Conditions Observatory data, between 2007 and 2010 incidence rates fell by 30\% for national workers and by $43 \%$ for immigrant workers. Moreover, data from table 1 also show there has been an increase in the duration of sick leave periods of over three days (over five days in the case of immigrants from more advanced countries) regardless of worker origin. These data would seem to suggest that the economic crisis has led to a reduction in the number of less serious accidents reported as well as a reduction in the gap between the durations of national and immigrant sick leave spells.

As for the gender variable, data in table 1 reflect longer sick leave periods among Spanish female workers which, coupled with lower incidence rates, might indicate that fewer accidents are being reported or point to physiological differences which increase post injury recovery time. However, in the case of female immigrant workers, sick leave periods are shorter than their male counterparts, and might point to worse working conditions in this group.

\section{RESULTS.}

\subsection{Stochastic frontier estimation.}

Having established the existence of substantial differences in sick leave

\footnotetext{
${ }^{6}$ The incidence rate used concurs with that calculated by the National Work Conditions Observatory, and is obtained as a quotient between accidents multiplied by 100,000 divided by the total number of those working. Applying this definition, the incidence rate among national workers drops from 4,585.3 in 2007 to 3,199 in 2010, and for immigrant workers from 4,286.1 to 2,448.9.
} 
duration between national and immigrant workers from a descriptive standpoint, the following step is to conduct multivariate analysis that will allow us to pinpoint "ceteris paribus" the effects of each variable. This enables us to isolate the pure nationality effect as an indicator of existing working conditions. To do this, as explained in the methodology section, we decided to apply stochastic frontier estimation.

When specifying the frontier model to be estimated, it is necessary to detail which variables will be included within the frontier and which others will be linked to inefficiency. As already mentioned, the frontier establishes the minimum duration which in our view can only be the result of medical and physiological factors. A group of 12 dummy covariates were selected as variables related to injuries, each variable describing the nature of the injury suffered. A group of 3 dummies were chosen to measure the severity of the injury. A further group of 7 dummies detailing which part of the body was affected. A further variable indicated whether primary care was provided in hospital or at a health centre or doctor's surgery. Another variable specified whether the worker required subsequent hospitalisation, and a final variable identified whether the injury was new or a relapse from a former injury. In addition, a further two variables sought to reflect a range of the injured worker's physiological aspects. The first of these was age, due to the impact it might have on worker recovery ${ }^{7}$. The second was a dummy variable that takes the value 1 if the worker is male and 0 if they are female, since it is felt that there may also be physiological differences between men and women which might have a bearing on their recovery ${ }^{8}$.

As regards the variables included to measure inefficiency, we considered any which might influence the recovery period and which might be linked to specific working conditions. These were basically variables of a certain "economic" nature and which have often been taken into account in the economic literature addressing work absenteeism and with regard to issues of "moral hazard" in work accident insurance. All of these variables were introduced gradually so as to isolate the effect of variables related to worker origin. Thus, in model 1 only two explanatory dummies were included, one taking the value 1 when the injured worker is from a developed country other than Spain, and 0 otherwise, together with another that takes the value 1 when the injured worker is from a non-developed country, and 0 in the remaining cases. Apart from origin-related variables, model 2 includes industry control covariates (10 industry groups in line with $\mathrm{NACE}^{9}$ ) and occupation control covariates (10 groups of occupations in line with the National Occupational Classification (NOC)), and one group of dummies

\footnotetext{
${ }^{7}$ This variable is also included squared so as to reflect the possible non-linear effects of injured worker ageing.

8 Martín-Román and Moral (2008) report higher proportion of hard-to-diagnose injuries among Spanish women once medical and physiological factors were accounted for.

${ }^{9}$ NACE stands for "Nomenclature of Economic Activities in the European Community". Although in 2007 data were classified following NACE93 and in 2010 following NACE09, a ten industry grouping has been carried out for each year so as to provide a homogeneous classification.
} 
detailing the Autonomous Community (Region) where the accident occurred $^{10}$. In addition to those previously mentioned, model 3 also includes two variables reflecting the contractual relationship; one dummy variable measuring whether the contract is open-ended ${ }^{11}$, and another covariate reflecting amount of workers' compensation ${ }^{12}$. Model 4 also includes variables of age and age squared to measure the non-linear effect on worker behaviour related to sick leave duration. Finally, model 5 adds a variable that takes the value 1 in 2010 and zero in 2007, and which measures the impact of the economic downturn. This model also includes another variable reflecting the importance of injuries that are hard-to-diagnose ${ }^{13}$ when accounting for the differences between actual and minimum duration. In consonance with the literature, injuries most likely to induce opportunistic worker behaviour are those called hard-to-diagnose (Fortin and Lanoie, 2000), easy-to-conceal (Smith, 1990), or soft-tissue injuries (Butler et al., 1996). These are basically strains, sprains, and lower back pains.

\section{(Insert table 2)}

The estimations carried out are based on a cost frontier ${ }^{14}$ where inefficiency is modelled following an exponential function. Table 2 shows the results of these estimations for the five previously defined models. The upper part of the table shows the coefficients of the variables used to model the frontier, whilst the lower part reflects the modelling of inefficiency. If we first analyse the results concerning the variables that determine the frontier or minimum duration, both the high significance of the coefficients as well as their homogeneity in all the specifications stand out. All the signs of the variables related to the injury prove coherent with what was expected a priori. Thus, minimum duration increases with injury severity, admission to hospital, and when the injury is a consequence of a relapse of a previous accident. As regards physiological variables such as gender and age, it can be seen on the one hand that age extends sick leave duration at an increasing rate, and on the other that men evidence a slightly lower minimum sick leave duration than women.

Yet, the most salient conclusions for the purposes of the present study emerge from the analysis of factors affecting inefficiency. This is where differences might be reflecting contrasting working conditions which translate to longer or shorter recovery periods. An overall analysis of the five models confirms that immigrants, and particularly those from less developed

\footnotetext{
${ }^{10}$ Corrales et al (2008) report significant differences in the duration of sick leave duration resulting from work-related accidents in the Spanish regions.

${ }^{11}$ The literature has often established the impact of the type of contract on the reported rate of accidents (Hernanz and Toharia, 2006; Amuedo-Dorantes, 2002 and Guadalupe, 2003).

${ }^{12}$ For a review of the effects of workers' compensation on the accident rate, see the analysis carried out in Fortin and Lanoie, (2000).

${ }^{13}$ Moral et al (2010) find differences in the percentage of hard-to-diagnose accidents reported by national and immigrant workers.

${ }^{14}$ The $\log$ likelihood tests ratio reveal a cost frontier with a significance level of $1 \%$. However, when positing a production frontier, this does not prove significant.
} 
areas, have fewer "economic days off", which we interpret as an indicator of poorer working conditions. This effect proves highly significant in all specifications and hardly varies when changing the model.

Going into detail for each model, further conclusions may be drawn. Including covariates for region, industry and occupation in model 2 reduces the size of the coefficient for immigrants from less developed countries and increases that of advanced ones, indicating that certain differences in sick leave duration are due to the particular jobs and industries the workers are engaged in. Model 3 shows a small reduction in both coefficients. This finding reveals that a further significant part of the differences may be due to the greater proportion of national workers with an open-ended contract and to the higher compensation they are awarded. The age variables in model 4 prove to be significant and do not affect differences in duration between nationals and immigrants. The only effect they do generate is to reduce the coefficient of the type of contract variable, which is no doubt the result of workers being more likely to have an open-ended contract as they get older. Finally, model 5 completes the specification by including a variable that reflects the impact of the crisis together with another denoting whether the injury was a strain, a sprain, or lower back pain. Both variables display positive and significant coefficients indicating that when diagnosis proves difficult, and during the crisis period, the number of "economic days off" increases. These findings suggest that longer sick leave periods during the crisis are not only the result of more serious work accidents.

\subsection{From logarithmic estimation to actual duration.}

Although the results concerning the estimations and the coefficients offer clear conclusions regarding which variables prove most relevant when determining sick leave duration, it seems appropriate to go one step further and translate these conclusions into days so as to obtain a more direct and "friendly" interpretation of the findings. One advantage of the frontier approach is that it enables a prediction of the part of the duration which is linked to the frontier and the part which is due to inefficiency for each one of the accidents. In turn, this allows certain interesting descriptive statistics linked to the economic downturn, origin, or gender, to be drawn. Nevertheless, because the estimation is carried out using a logarithmic specification, it requires a transformation to correct possible prediction underestimation, expressed as follows:

$D^{r}=\exp ^{d^{r}}>\exp ^{\left(\widehat{d_{l}^{s}}+\widehat{u_{\imath}}\right)}$

Following Hernández and Rojas (2011), the underestimation associated with equation (6) may be corrected for by using an auxiliary regression that provides predictions which are biased but which are consistent and not subject to residual normality. 
$D^{r}=\widehat{\alpha_{0}} \cdot \exp ^{\left(\widehat{d_{l}^{s}}+\widehat{u_{l}}\right)}$

From here, undoing the logarithmic transformation allows us to calculate the equivalence in days of each of the components.

$D^{r}=\widehat{\alpha_{0}} \cdot \exp ^{\left(\widehat{d_{l}^{s}}+\widehat{u_{l}}\right)}=\widehat{\alpha_{0}} \cdot \exp ^{\widehat{d^{S}}}+\widehat{\alpha_{0}} \cdot\left(\exp ^{\left(\widehat{d_{l}^{s}}+\widehat{u_{\imath}}\right)}-\exp ^{\widehat{d_{l}^{s}}}\right)=\widehat{D^{s}}+\widehat{D^{i}}(8)$

where $\widehat{D^{l}}$ refers to the duration linked to inefficiency. Using the decomposition shown in equation (8) we build table 3, which details the estimated durations related to the frontier and to inefficiency. This depicts the value of these durations for national workers and immigrant workers, and for disaggregation into gender and year of accident. The first three rows refer to the minimum duration linked to medical and physiological factors (what we have called "medical days off") and the last three to the period of recovery linked to working conditions (the so-called "economic days off").

\section{(Insert table 3)}

In the light of the data to emerge from table 3, it can be seen that most of the differences in sick leave duration amongst workers are due to inefficiency, which in the present work is used as an indicator of working conditions. As regards immigrant worker origin, a central variable in our analysis, minimum sick leave duration is seen to be extremely similar among national workers and immigrant workers from developed countries, and a little over one day less in the case of those from less advanced countries. This finding may be consistent with workers from less developed countries being more concentrated in occupations where accidents are less serious. Yet, the period associated to so-called economic sick-leave days ranges between fewer than nine days for immigrant workers from less advanced countries in the year prior to the onset of the downturn to over 15 days among immigrants from more advanced countries and to over 17 days in the case of Spanish workers in 2010. This finding seems to point to noticeable differences in the level of employment protection afforded to each worker in their job and therefore the kind of working conditions they enjoy. Delving more deeply, it is immigrant workers, and particularly those from less developed countries, who enjoy fewer economic sick leave days, and who must therefore endure the least favourable working conditions.

As regards the gender variable, no appreciable differences appear between men and women, either in standard duration or in inefficiency. Nor, indeed, do said differences always go in the same direction. Whereas the minimum duration tends to be longer in the case of women in overall terms, inefficiency is only higher for Spanish women, whilst immigrant women present fewest economic sick leave days. The former part of said finding might indicate that women suffer more serious accidents or that they might require a longer minimum recovery time due to physiological reasons, 
whereas the latter finding might suggest that it could be foreign women who are forced to put up with the most adverse working conditions.

The business cycle does, however, prove significant, increasing standard duration by almost one day, and the recovery period by over three. This leads us to draw a two-fold conclusion. On the one hand, the greater number of days absent due to physiological reasons during the crisis points to more serious injuries than reported, and on the other, the number of "economic days off" in 2010 being higher seems to point to a certain degree of moral hazard. Our tentative explanation would be that, due to the fear of being dismissed and losing their labour income, some workers prolong their sick leave in order to receive workers' compensation for some extra days. In this sense, we have to notice that workers' compensation is more generous than unemployment benefit so that there could also exist an insurance substitution moral hazard (Fortin and Lanoie, 2000).

\section{CONCLUSIONS.}

The main goal of the present work is to pinpoint differences in the working conditions between workers of different nationalities. To achieve this, we make use of an important dimension in the labour market, namely workplace accidents, by means of a variable such as sick leave duration. Longer sick leave may be open to a two-fold interpretation. On the one hand, it may point to more serious accidents, while on the other it may indicate that injured workers enjoy a longer period of recovery, in which case it would suggest better working conditions.

In order to draw a distinction between these two interpretations, we conducted a stochastic frontier estimation. Said technique is able to break down sick leave duration into two components: the first relates to purely physiological or medical factors, and may be deemed the minimum duration for a sick leave, while the second is considered in frontier literature as inefficiency. In the present work, this reflects differences in behaviour associated to characteristics of the worker in question and the nature of the job. It is this latter component which is used as an indicator of a worker's working conditions. Thus, it would seem logical to assume that if longer sick leave duration were due to more serious accidents we would find differences both in the minimum duration as well as in inefficiency. However, if a longer sick leave period were the result of better working conditions, any differences would basically be apparent in the latter component.

Findings both at a descriptive level as well as subsequent to estimation underpin the existence of contrasting working conditions for national workers and immigrant workers. Foreign workers, and particularly those from less developed countries enjoy fewer economic sick leave days and therefore endure poorer working conditions. 
Finally, including the business cycle and gender as explanatory variables allows us to draw a number of additional conclusions. Firstly, it can be seen that the downturn has led to accidents that entail longer minimum sick leave duration and therefore more serious accidents, whereas the substantial increase in days associated to inefficiency might also be pointing to a certain degree of moral hazard linked to insurance substitution moral hazard. Secondly, and with regard to gender, no major differences are apparent between men and women, either in minimum duration or inefficiency, within the same nationality group.

\section{REFERENCES.}

Ahonen, E.Q. and Benavides, F.G. (2006): "Risk of fatal and non-fatal occupational injury in foreign workers in Spain". Journal of Epidemiology and Community Health, 60. 424-426.

Aigner, D., C. Lovell, and Schmidt P. (1977): "Formulation and estimation of stochastic frontier production function models". Journal of Econometrics. 6(1): 21-37.

Amuedo-Dorantes, C. (2002): "Work safety in the context of temporary employment: the Spanish experience". Industrial and Labor Relations Review. 55(2), 262-272

Amuedo-Dorantes, C. and De la Rica, S. (2006): "Labor Market Assimilation of Recent Immigrants in Spain“, IZA DP 2104.

Amuedo-Dorantes, C. and De la Rica, S. (2010): “Immigrants' responsiveness to labor market conditions and their impact on regional employment disparities: evidence from Spain". SERIEs. 1(4). 387-407

Battese, G. E. and Coelli, T. (1995): "A model for technical inefficiency effects in a stochastic frontier production function for panel data". Empirical Economics. 20: 325-332.

Battese, G.E., and Cora, G.S. (1977): "Estimation of a production frontier model: with application to the pastoral zone of Eastern Australia". Australian Journal of Agricultural Economics. 21(3): 169-179

Borjas, G.J. (1999): “The Economic Analysis of Immigration”, in Ashenfelter 0. and Card D. (eds.): Handbook of Labor Economics, vol. 3A, ed. NorthHolland.

Butler R J, Durbin D L, Helvacian N. M. (1996): "Increasing claims for soft tissue injuries in workers' compensation: cost shifting and moral hazard". Journal of Risk and Uncertainty. 13: 73-87.

Card, D. (2005): "Is New Immigration Really so Bad?" The Economic Journal. 115: 300-323.

Carrasco, R., Serrano, C. and Malo, M.A. (2003): "Mercado de trabajo e inmigración". en A. Izquierdo (ed.): Inmigración, mercado de trabajo y protección social en España, ed. Consejo Económico y Social.

Carrasco, R., Jimeno, J.F. and Ortega, A.C. (2008): "The Effect of Immigration on the Employment Opportunities of Native-Born Workers: Some 
Evidence for Spain". Journal of Population Economics. 3/08.

Corrales, H., Martín-Román and Moral de Blas, A. (2008): "La duración de las bajas por accidente laboral en España: ¿Se justifican las diferencias entre comunidades autónomas?" Revista de Economía Laboral. 5(1): 73-98.

Fortin, B. and Lanoie, P. (2000). Incentive Effects of Workers' Compensation Insurance: a Survey, Handbook of Insurance, Springer, 421-458.

Friedberg, R.M.; Hunt, F. (1995): "The Impact of Immigrants on Host Country Wages, Employment and Growth". Journal of Economic Perspectives. 9 (2): 23-44.

Garrido, L. and Toharia, L. (2004): “La situación laboral de los españoles y los extranjeros según la Encuesta de Población Activa". Economistas. 99: 74-86.

Greene, W. (1980a): "Maximum likelihood estimation of econometric frontier functions". Journal of Econometrics. 13: 27-56.

Greene, W. (1980b): "On the estimation of a flexible frontier production model". Journal of Econometrics. 13: 101-115.

Guadalalupe (2003): "The hidden cost of fixed term contracts: the impact on work accidents". Labour Economics. 10: 339-357

Hernández J. C. and Rojas C. (2011): "Metodología de estimación de Diplomados en Estadística del Estado en las delegaciones provinciales del INE". Documentos de Trabajo INE 09/2011.

Hernanz, V. and Toharia, L. (2006): "Do temporary contracts increase work accidents? A microeconometric comparison between Italy and Spain". Labour. 20 (3): 475-504.

Iglesias, C. and Llorente, R.(2008): “Efectos de la inmigración en el mercado de trabajo español". Economía Industrial. 367: 85-92

Izquierdo, M. and Jimeno, J.F. (2005): "Inmigración: desarrollos recientes y consecuencias económicas”. Boletín Económico del Banco de España. Febrero: 41-49.

Jondrow, J., Lovell, C. A. K., Materov, I. S. and Schmidt, P. (1982): “On the estimation of technical inefficiency in the stochastic frontier production function model". Journal of Econometrics. 19: 233-238.

Lalonde, R.J. and Topel, R.H. (1997): "The economic impact of international migration and the economic performance of migrants", in Rosenzweig and Stark (eds.): Handbook in population and family economics, ed. Elsevier Science.

Medina, E., Herrarte, A. and Vicens, J. (2010): "Inmigración y desempleo en España: Impacto de la crisis económica". Información Comercial Española, ICE: Revista de economía. 854: 37-48

Meeusen W. and Van den Broeck J. (1977). "Efficiency estimation from CobbDouglas production function with composed errors". International Economic Review. 18(2): 435-444.

Martin-Roman, A. and Moral, A. (2008): "Moral hazard and gender differences in the workplace accidents insurance". Empirical Economics Letters. 7(7): 707-713.

Moral A., Martín-Román, A. and Rodríguez, J. C. (2010): “La antigüedad y las 
diferencias de esfuerzo entre trabajadores de distintas zonas geográficas: un estudio de los accidentes de trabajo". Estudios de Economía Aplicada. 28 (1): 1-20

Simon, H., Sanromá, E. and Ramos, R. (2008): "Labour segregation and immigrant and native-born wage distributions in Spain: an analysis using matched employer-employee data". Spanish Economic Review. 10: $135-168$.

Smith R. S. (1990): "Mostly on Monday: is workers' compensation covering off-the-job injuries?" In Benefits, Costs, and Cycles in Workers' Compensation, Borba P S, Appel D. (eds.), Kluwer Academic Publishers: Boston. 115-127.

Stevenson, R. (1980): "Likelihood functions for generalized stochastic frontier functions". Journal of Econometrics. 13: 57-66. 
Table 1: Workplace accident sick leave duration by nationality of injured worker.

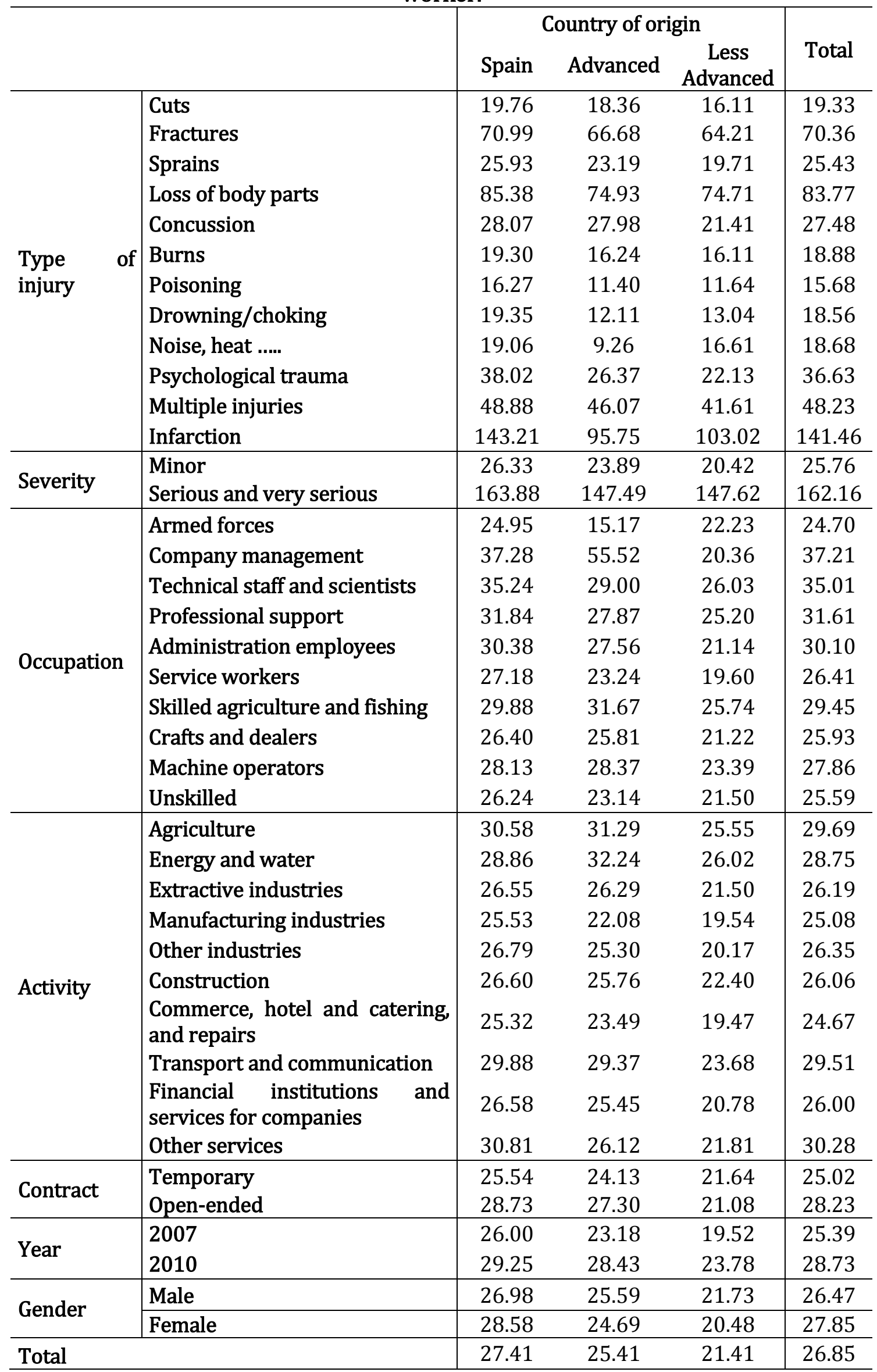

Source: Own, based on SAW data 
Table 2: Stochastic frontier estimation of sick leave duration.

\begin{tabular}{|c|c|c|c|c|c|}
\hline & Model 1 & Model 2 & Model 3 & Model 4 & Model 5 \\
\hline \multicolumn{6}{|c|}{ Frontier } \\
\hline Type of injury & Yes & Yes & Yes & Yes & Yes \\
\hline Part of the body affected & Yes & Yes & Yes & Yes & Yes \\
\hline Hospitalised & $0.186^{* * *}$ & $0.186^{* * *}$ & $0.185^{* * *}$ & $0.186^{* * *}$ & $0.187^{* * *}$ \\
\hline Primary care in hospital & $0.669 * * *$ & $0.661^{* * *}$ & $0.660^{* * *}$ & $0.659^{* * *}$ & $0.661^{* * *}$ \\
\hline Serious accident & $1.048^{* * *}$ & $1.051^{* * *}$ & $1.053^{* * *}$ & $1.058^{* * *}$ & $1.055^{* * *}$ \\
\hline Very serious accident & $0.490^{* * *}$ & $0.490^{* * *}$ & $0.491^{* * *}$ & $0.496^{* * *}$ & $0.514^{* * *}$ \\
\hline Relapse & $0.393^{* * *}$ & $0.393^{* * *}$ & $0.390^{* * *}$ & $0.388^{* * *}$ & $0.385^{* * *}$ \\
\hline Age & $0.010^{* * *}$ & $0.009 * * *$ & $0.008^{* * *}$ & $-0.005^{* * *}$ & $-0.004^{* * *}$ \\
\hline Age squared & $1.8 \mathrm{E}-05^{* * *}$ & $2.9 \mathrm{E}-05^{* * *}$ & $3.9 \mathrm{E}-05^{* * *}$ & $1.5 \mathrm{E}-04^{* * *}$ & $1.4 \mathrm{E}-04^{* * *}$ \\
\hline Male & $-0.087^{* * *}$ & $-0.083^{* * *}$ & $-0.088^{* * *}$ & $-0.087^{* * *}$ & $-0.087^{* * *}$ \\
\hline Constant & $1.601^{* * *}$ & $1.614^{* * *}$ & $1.635^{* * *}$ & $1.927^{* * *}$ & $1.950^{* * *}$ \\
\hline \multicolumn{6}{|c|}{ Inefficiency } \\
\hline Region & No & Yes & Yes & Yes & Yes \\
\hline Occupation & No & Yes & Yes & Yes & Yes \\
\hline Industry & No & Yes & Yes & Yes & Yes \\
\hline \begin{tabular}{|l|} 
Immigrant from an \\
advanced country \\
Immigrant from less- \\
advanced country \\
\end{tabular} & $\begin{array}{l}-0.173^{* * *} \\
-0.455^{* * *}\end{array}$ & $\begin{array}{l}-0.186^{* * *} \\
-0.391^{* * *}\end{array}$ & $\begin{array}{l}-0.169^{* * *} \\
-0.367^{* * *}\end{array}$ & $\begin{array}{l}-0.172^{* * *} \\
-0.373^{* * *}\end{array}$ & $\begin{array}{l}-0.173^{* * *} \\
-0.376^{* * *}\end{array}$ \\
\hline Open-ended contract & & & $0.076^{* * *}$ & $0.022^{* * *}$ & $0.011^{* * *}$ \\
\hline Compensation & & & $0.002^{* * *}$ & $0.001^{* * *}$ & $0.001^{*}$ \\
\hline Age & & & & $0.069^{* * *}$ & $0.066^{* * *}$ \\
\hline Age squared & & & & $-0.001^{* * *}$ & $-0.001^{* * *}$ \\
\hline Hard-to-diagnose injury & & & & & $0.208^{* * *}$ \\
\hline Downturn & & & & & $0.123^{* * *}$ \\
\hline Constant & $-1.066^{* * *}$ & $-0.994^{* * *}$ & $-1.114^{* * *}$ & $-2.685^{* * *}$ & $-2.741^{* * *}$ \\
\hline
\end{tabular}

Source: Own, based on SAW data.

Note: ${ }^{* * *}, * *, *$ indicate significance levels of $1 \%, 5 \%$, and $10 \%$ respectively 
Table 3: Estimated durations for minimum duration and inefficiency by country of origin

\begin{tabular}{l|l|cc|cc|}
\hline \multirow{2}{*}{} & \multicolumn{2}{|c|}{ Gender } & \multicolumn{2}{c|}{ Year } \\
\cline { 3 - 6 } & \multicolumn{2}{|c|}{ Female } & Male & 2007 & 2010 \\
\hline $\begin{array}{l}\text { Minimum } \\
\text { duration } \\
\begin{array}{l}\text { (Medical days } \\
\text { off) }\end{array}\end{array}$ & $\begin{array}{l}\text { Spain } \\
\text { Developed } \\
\text { countries } \\
\text { Non-developed } \\
\text { countries }\end{array}$ & 16.29 & 15.34 & 15.29 & 15.99 \\
\hline & 16.29 & 15.82 & 15.62 & 16.31 \\
$\begin{array}{l}\text { Inefficiency } \\
\text { (Economic } \\
\text { days off) }\end{array}$ & $\begin{array}{l}\text { Spain } \\
\text { Developed } \\
\text { countries } \\
\text { Non-developed } \\
\text { countries }\end{array}$ & 16.80 & 14.49 & 14.33 & 14.85 \\
\hline
\end{tabular}

Source: Own, based on SAW data.

Note: The sum of minimum duration and inefficiency does not coincide with actual data since the estimation is biased. 